\title{
Wireless Power Transfer Based on Magnetic Coupling
}

\author{
Wang Bin $^{1, a}$, Wang Zezhong ${ }^{1, b}$ \\ ${ }^{1}$ North China Electric Power University , Beijing China \\ ackwbncepu@126.com, bwzzh@ncepu.edu.cn
}

Keywords: induction coupling; wireless power transfer; circuit model; loosely coupled transformer.

\begin{abstract}
Wireless transmission of electric energy has always been a dream for people. The wireless power transmission technology based on induction coupling is the easiest way. We studied the factors that affect the magnetic coupling wireless power transmission system by combining the theory, the software simulation and the experiment. The main work of this paper is as follows. We analyzed the circuit model of the magnetic coupling wireless power transmission system, studied the reactive power compensation problem under power frequency and high frequency, produced a kind of loosely coupled transformer and calculated its parameters, used ANSYS software to simulate the loosely coupled transformer.
\end{abstract}

\section{Significance of wireless power transmission}

The advancement of human civilization has been accompanied by the development of energy. Events of the first industrial revolution represented by steam power and the second industrial revolution represented by electric power indicate that the advancement of energy application technologies has always been the precondition of cultivation's progress[1].

The traditional power transmission mode has its limitations, such as transmission loss, aging lines, point discharge, which could significantly reduce the reliability and safety of the system. The traditional power supply with cable in some special areas including mine fields and seabed has serious safety flaws. It's inconvenient for us to live in the surroundings with crisscross cables. Correspondingly, wireless power transmission has its own advantages. First, it could avoid the crisscross cables. In addition, for the above-mentioned problems occurring in special areas, the special wireless transmission could prevent safety accidents. Some mobile electric devices, such as electric vehicles, could be charged at any time, which reduces the demands for the greater capacity of battery. Especially, with wireless charging, there is no need to carry the various complicated power lines for mobile device such as mobile phone and digital camera[2,3,4,5].

Compared with the traditional power transmission, the wireless transmission has the advantage of not only flexibility and convenience but also higher level of safety. Without complicated power lines and power sources, the potential safety risks could be significantly reduced. Thus, the technology has important application values in some fields, such as military, aerospace, aviation, urban electrified transportation, industrial robots and transportation equipments. It also has bright future when it's applied in domestic electronic products, biomedicine, and disaster-prevention and rescue[6,7].

\section{Evaluation and analysis of coreless coils}

It's the theory of mutual inductance that the inductive coupling technology applies. The primary circuit and secondary circuit have no directly electric connection, but are connected through magnetic coupling. Meanwhile, the change of the number of coil's turns could achieve the purpose of voltage transformation. At present, in studies and applications of transmitting electric energy through inductive coupling technology, the theory of separation transformer has been put into usage. This technology's greatest advantages are its easy theory, easiness to be realized, and high efficiency of transmitting energy at short distance, which is as high as 99\%. Meanwhile, it has obvious disadvantages, such as that only if the primary circuit and the secondary circuit are aligned 
with each other as much as possible could the requirements of transmission could be met, otherwise, the efficiency would be reduced significantly. Therefore, this technology has strict requirements for the positions of the first and second loop as well as the iron core[8,9,10].

\section{Circuit of the system}

The wireless transmission system based on the inductive coupling technology designed by us has four parts, which are respectively the power supply, emitter, receiver and load.

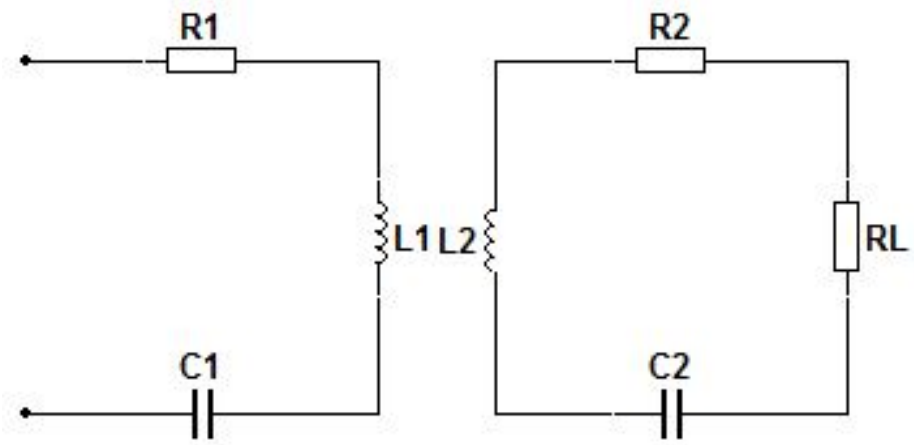

Fig.1 Circuit of the system

Fig 2-1 is the system circuit based on the mutual inductance. In the system designed by us, the signals produced by the power supply are transmitted into inductance coil L1, then, the emitting coils transmit the electric energy into receiving coils L2 by way of magnetic inductance coupling. The energy is transmitted by the emitter into the receiver with certain distance away, then, transmitted into the load, which completes the task of wireless transmission of energy. At first, we will analyze the coreless coil which is easily achieved and explore the working situation under power frequency. During the exploration, based on coreless coils with 275 turns, and given domestic electric energy usage, the number of turns of the mutual inductance coils is gradually adjusted under the condition of load voltage being $220 \mathrm{~V}$ to make sure that system's requirement for voltage is about $220 \mathrm{~V}$. The inside and outside radius of coil with 275 turns is respectively $0.25 \mathrm{~m}$ and $0.36 \mathrm{~m}$, and the self-inductance is computed to be $0.071919 \mathrm{H}$; the diameter of the enameled wire is $2.04 \mathrm{~mm}$; the distance between the centers of two coils is $2 \mathrm{~cm}$; the filling coefficient of coil is computed to be 0.7442 ; the load is $13.75 \Omega$; the voltage on the load is $220 \mathrm{~V}$; the capacitance compensation employs completely compensation. With the self-designed volume integral software to compute the self-inductance and mutual inductance of mutual inductance coils, the exploration is gradually conducted and the gotten main data is shown in table 1.

It's shown that under condition of power frequency, since the mutual inductance among coils is relatively small and the coupling of mutual inductance coils is relatively bad, when transmission of $220 \mathrm{~V}$ voltage is required by the load, the input voltage and input current are relatively high, and the efficiency of the system isn't good. In addition, for the coils with 275 turns, its self-inductance is $0.071919 \mathrm{H}$ and the compensation capacitance required by complete compensation is $221 \mu \mathrm{F}$. Problems may occur when the compensation capacitor is chosen, such as that film capacitor is strong enough to withstand the voltage but its capacitance is too small; the capacitance of the supercapacitor is too big and it can't withstand voltage; the electrolytic capacitor can't be applied in AC circuit and the electrolytic capacitance without polarity is used in the circuit and couldn't run long. Therefore, there are two resolutions for the above-mentioned problems, i.e. improving the working frequency of the system or employing the structure of iron core to improve the self-inductance and mutual-inductance of the coils. The method of improving the working frequency is used by many electric devices with low power to get charged without wire. Given that the electric devices confronted by us are the ones with relative big power and the requirement of simplifying system needs to be met, we make our mind to use the iron core to improve the self-inductance and mutual inductance of coils. 
Table 1. The calculation results of the coreless coils with different turns

\begin{tabular}{|c|c|c|c|c|}
\hline Turns Ratio & Mutual Inductance[H] & Input Voltage[V] & Input Current[A] & Efficiency[\%] \\
\hline 275: 275 & 0.056632 & 383.8118 & 17.59273 & 62.09 \\
\hline 275: 250 & 0.046445 & 340.446 & 20.58073 & 59.83 \\
\hline 275: 325 & 0.061663 & 425.7383 & 16.75892 & 58.76 \\
\hline 275: 350 & 0.064373 & 426.7175 & 17.70843 & 55.49 \\
\hline 275: 400 & 0.059415 & 413.5799 & 21.07141 & 48.11 \\
\hline 275: 200 & 0.023011 & 262.914 & 35.29551 & 37.95 \\
\hline 275: 175 & 0.014335 & 301.1892 & 54.91079 & \\
\hline 200: 200 & 0.019869 & 189.3179 & 40.87768 & 45.51 \\
\hline 200: 150 & 0.00927 & 227.3217 & 82.5585 & \\
\hline 150: 150 & 0.007539 & 166.677 & 101.5111 & \\
\hline $220: 275$ & 0.044841 & 268.8029 & 20.36748 & 64.35 \\
\hline 220: 214 & 0.035184 & 229.0914 & 24.48899 & 62.8 \\
\hline $220: 250$ & 0.036785 & 235.8182 & 23.8715 & 63.73 \\
\hline 220: 220 & 0.02478 & 196.4346 & 33.66658 & 53.26 \\
\hline
\end{tabular}

\section{Core design and experiments of loosely coupled transformer}

The above analysis indicates that the design of iron core under power frequency could improve the self-inductance and mutual inductance of coils, which is to design loosely coupled transformer to complete the wireless transmission of electric power. Since the structure of iron core could affect the self-inductance and mutual inductance of loosely coupled transformer as well as the coupling coefficient, the design of the structure of iron core could directly affect the performances of the transformer. We designed various iron cores with different forms and used the software of ANSYS to computer and analyze the different structures of iron cores under the conditions of air gaps with different length. The structure of the iron cores is shown in fig 2.

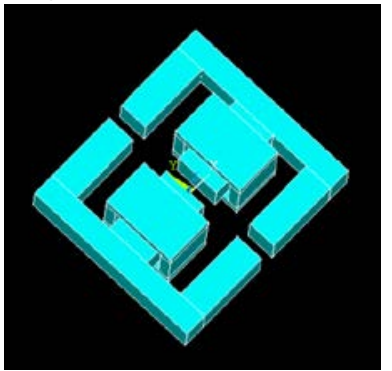

(a) Double E

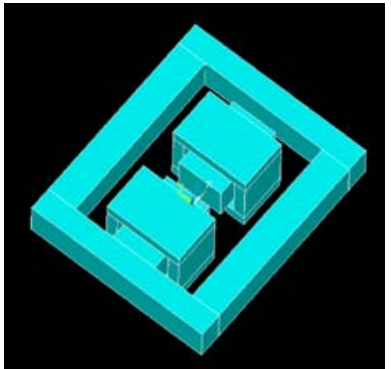

(b) Embedded

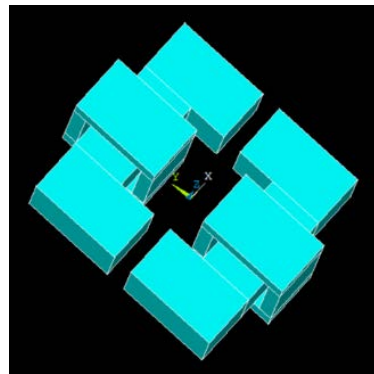

(c) Square

Fig. 2 The structure of the iron cores

\section{Analysis of the iron cores with different structure}

Double E-type core. The difference between this iron core and the transformer with one phase and three columns is that an air gap exists in the middle of this iron core. For air gaps with different length, the results simulated and computed with the help from ANSYS are shown in table 2. 
Table 2. The calculation results of Double E-type core

\begin{tabular}{ccccc}
\hline Air gap[mm] & $\begin{array}{c}\text { Self-inductance } \\
\text { L1[H] }\end{array}$ & $\begin{array}{c}\text { Self-inductance } \\
\text { L2[H] }\end{array}$ & $\begin{array}{c}\text { Mutual } \\
\text { inductance M[H] }\end{array}$ & $\begin{array}{c}\text { Coupling } \\
\text { coefficient k }\end{array}$ \\
\hline 1 & 0.59648 & 0.60577 & 0.47578 & 0.7915 \\
2 & 0.39631 & 0.39744 & 0.27399 & 0.6903 \\
3 & 0.3249 & 0.33409 & 0.19978 & 0.6064 \\
4 & 0.28373 & 0.29015 & 0.15991 & 0.5573 \\
5 & 0.26221 & 0.26692 & 0.13373 & 0.5054 \\
6 & 0.25197 & 0.25625 & 0.11533 & 0.4539 \\
7 & 0.24126 & 0.23927 & 0.10079 & 0.4195 \\
8 & 0.22766 & 0.22822 & 0.09009 & 0.3952 \\
9 & 0.22046 & 0.23382 & 0.08135 & 0.3554 \\
10 & 0.21489 & 0.21669 & 0.07413 & 0.3435 \\
\hline
\end{tabular}

Embedded-type core. The advantage of the embedded iron core is that the system weight on one side is reduced as much as possible during the designing process to meet the requirements of the mobile devices. For air gaps with different length, the results simulated and computed with the help from ANSYS are shown in table 3.

Table 3. The calculation results of Embedded-type core

\begin{tabular}{ccccc}
\hline Air gap[mm] & $\begin{array}{c}\text { Self-inductance } \\
\text { L1[H] }\end{array}$ & $\begin{array}{c}\text { Self-inductance } \\
\text { L2[H] }\end{array}$ & $\begin{array}{c}\text { Mutual } \\
\text { inductance M[H] }\end{array}$ & $\begin{array}{c}\text { Coupling } \\
\text { coefficient k }\end{array}$ \\
\hline 1 & 0.45944 & 0.58323 & 0.40164 & 0.7759 \\
2 & 0.28391 & 0.39708 & 0.22616 & 0.6736 \\
3 & 0.23202 & 0.34653 & 0.1701 & 0.6022 \\
4 & 0.19629 & 0.31195 & 0.13334 & 0.5389 \\
5 & 0.17653 & 0.28281 & 0.11254 & 0.5037 \\
6 & 0.16354 & 0.27129 & 0.09337 & 0.4433 \\
7 & 0.15019 & 0.25575 & 0.08094 & 0.413 \\
8 & 0.13915 & 0.24449 & 0.07199 & 0.3903 \\
9 & 0.13358 & 0.25202 & 0.06552 & 0.3571 \\
10 & 0.12856 & 0.23506 & 0.05939 & 0.3417 \\
\hline
\end{tabular}

Square core. This iron core could minimize the volume and weight of the whole system when the cross-section of the iron core and the size of the coil are the same. For air gaps with different length, the results simulated and computed with the help from ANSYS are shown in table 4.

Table 4. The calculation results of Square core

\begin{tabular}{ccccc}
\hline Air gap[mm] & $\begin{array}{c}\text { Self-inductance } \\
\text { L1[H] }\end{array}$ & $\begin{array}{c}\text { Self-inductance } \\
\text { L2[H] }\end{array}$ & $\begin{array}{c}\text { Mutual } \\
\text { inductance M[H] }\end{array}$ & $\begin{array}{c}\text { Coupling } \\
\text { coefficient k }\end{array}$ \\
\hline 1 & 0.57494 & 0.57363 & 0.41701 & 0.7261 \\
2 & 0.39732 & 0.39671 & 0.23868 & 0.6012 \\
3 & 0.3345 & 0.33501 & 0.17443 & 0.5211 \\
4 & 0.30304 & 0.31961 & 0.14036 & 0.451 \\
5 & 0.28248 & 0.27905 & 0.12005 & 0.4276 \\
6 & 0.26404 & 0.26599 & 0.1035 & 0.3905 \\
7 & 0.25332 & 0.25232 & 0.09192 & 0.3636 \\
8 & 0.24834 & 0.24766 & 0.08308 & 0.335 \\
9 & 0.24377 & 0.24071 & 0.07658 & 0.3162 \\
10 & 0.23566 & 0.23402 & 0.07019 & 0.2989 \\
\hline
\end{tabular}

The advantages and disadvantages of different cores. Based on above simulation, the advantages and disadvantages of these iron cores could be obtained. The advantage of the Double 
E-type core is its highest coupling coefficient and the highest self-inductance and mutual inductance, which makes the system own the higher efficiency. Meanwhile, one side of this iron core is heavy and cumbersome, so it is inconvenient for manual operation. The advantage of embedded iron core is that its coupling coefficient is only second to that of the Double E-type core, and its one side is the lightest, so it is convenient for manual operation. However, its overall volume and weight is the largest among these three iron cores, which's unfavorable for the handiness of the device. For square iron core, its overall volume and weight are the smallest which could reduce the weight of the product. However, its coupling coefficient is the smallest and the self-inductance and mutual inductance is also small.

\section{Loosely coupled transformer with Double E-type core test}

Finally, we adopted the iron core with double E, and made the loosely coupled transformer. Its test system could be seen in fig 3 .

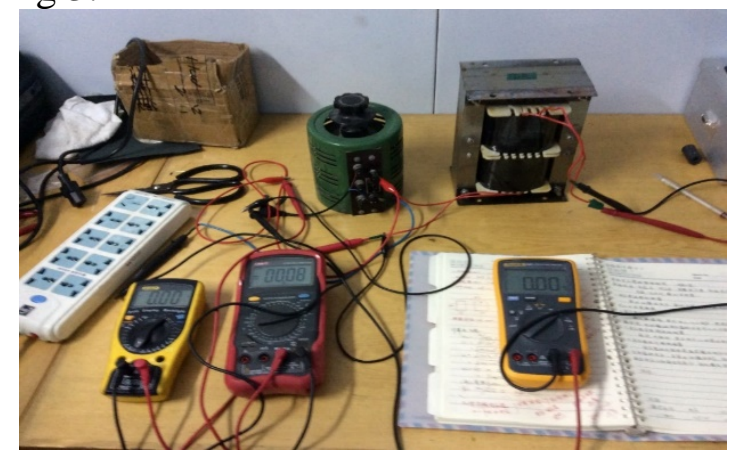

Fig. 3 Loosely coupled transformer with Double E-type core test

We took 5 tests to study the main parameters of the loosely coupled transformer.

Test 1 (Measurement of self-inductance and mutual inductance): Primary side was connected to the voltage of $220 \mathrm{~V}$ and the measurement showed that the no-load voltage of the second side was $209.7 \mathrm{~V}$ and current of primary side was $0.40 \mathrm{~A}$.Second side was connected to the voltage of $220 \mathrm{~V}$ and the measurement showed that no-load voltage of primary side was $209.0 \mathrm{~V}$ and current of the second side was $0.40 \mathrm{~A}$. The mutual inductance was computed to be $1.6687 \mathrm{H}$. The self-inductance of primary side of the coil was $1.7506 \mathrm{H}$ and the self-inductance of the second side of the coil was $1.7507 \mathrm{H}$. The compensation capacitance was $5.7878 \mu \mathrm{F}$ and the coupling coefficient was 0.9532 .

Test 2 (Measurement of iron loss): Primary side was connected to the nominal voltage of 220V. When the circuit of the second side was opened, the measurement showed that the voltage and current of the primary side was respectively $220.2 \mathrm{~V}$ and $0.39 \mathrm{~A}$. Then iron loss was computed to be 85.9W.

Test 3 (Measurement of copper loss): Primary side was connected to a small voltage and the second side was the nominal current. The measurement showed that the voltage and current of the primary side was respectively $31.66 \mathrm{~V}$ and $0.06 \mathrm{~A}$. The copper loss was computed to be $1.90 \mathrm{~W}$.

Test 4 (Load test): The nominal voltage was $150 \mathrm{~W}$ with compensation capacitance as $6 \mu \mathrm{F}$ and load as $293 \Omega$. The test results could be shown in table 5 .

Table 5. The results of load test

\begin{tabular}{cccc}
\hline Load voltage[V] & Load current[A] & Output Power[W] & Efficiency[\%] \\
\hline 214 & 0.73 & 156.2 & 63 \\
\hline
\end{tabular}

\section{Conclusion}

In conclusion, different structures of iron cores should be adopted for different applications. For example, if the mobile device has the requirement for handiness, the embedded-type core could be adopted; if the system has high requirements for volume and weight, the square iron core could be adopted; if the system has high requirement of coupling coefficient and efficiency, the double E-type core could be adopted. Based on the theory of mutual inductance, we proposed the method 
of wireless transmission based on loosely coupled transformer, and explored its practicability. It shows that under the condition High Power, its efficiency could reach $60 \%-80 \%$, which is sufficient for demands of domestic electric appliances.

\section{References}

[1] Wang Yixiong, Hu Jinlei, Liang Jun, Wang Changhua. Prospects application of wireless power transmission. Journal of Air Force Engineering University(Natural Science Edition)(2003), 4 (1) : 82-85.

[2] Tan Linlin, Huang Xueliang, Liu Hui, Huang Hui. Study of Wireless Power Transfer System Through Strongly Coupled Resonances. 2010 International Conference on Electrical and Control Engineering( 2010).

[3] Peter E. Glaser. Power from the sun: its future[J]. Science(1968). 162(3856): 857-861.

[4] Information on http://dsc. discovery. com/tv/project-earth/lab-books/power-plant/guide1. html.

[5] Kurs, A.Karalis, J.D.Joannopoulos, P.Fisher, and M.Soljacic. Wireless power transfer via strongly coupled magnetic resonances. Science(July 2007), 317:83-86.

[6] Soljacic M. Wireless non-radiative energy transfer. presentation archived at the website of American Institute of Physics.

[7] Zhen Ning Low, Raul Andres Chinga, Ryan Tseng. Design and test of a high-power high-efficiency loosely coupled planar wireless power transfer System[J]. IEEE Transactions on Industrial Electronics(2009), 56(5): 1801-1812.

[8] Zhen Ning Low, Raul Andres Chinga, Ryan Tseng. Design and test of a high-power high-efficiency loosely coupled planar wireless power transfer System[J]. IEEE Transactions on Industrial Electronics(2009), 56(5): 1801-1812.

[9] Stuart Robinson, Wireless Charging Will Quadruple its Potential if Combined with Speed-Charging [J], Handset Component Technologies(2009).

[10] Yungtaek jang, Milan MJovanvoic. A contactless Electrical energy transmission System of Portable-Telephone Battery Chargers [J], IEEE Transactions on Industrial Electronics 2003. 